\title{
Antisocial or Impulsive ? A case report on Adult ADHD and Antisocial Personality Disorder Comorbidity
}

\section{Background}

Antisocial personality disorder (APD) is characterized by a disregard or social and moral norms and others, impulsiveness, recklessness and unlawful behavior, leading to interpersonal and social difficulties. Specific Diagnostic riteria for APD are still under debate.

Adult Attention Deficit Hyperactivity Disorder (ADHD) affects up to $7.6 \%$ of adult patients, being present in about $60 \%$ of kids reaching adulthood. It is defined as inappropriate levels of inattention, hyperactivity or impulsivity causing impairment. The DSM 5 diagnostic criteria are divided between inattention criteria and hyperactivity and impulsivity symptoms (table 1). At least six or more criteria of one category must be present to make the diagnosis of predominantly inattentive or predominantly hyperactive presentation, or combined presentation if at least six criteria from both groups are met simultaneously. Symptoms must also be present prior to age 12 and in two or more settings, having functional impact and not being better accounted for by other mental disorders.

There is established association between ADHD and Personality Disorders with comorbidity ranging from 10 to $75 \%$ depending on samples, the most common being Antisocial Personality Disorder and Borderline Personality Disorder. ADHD significantly increases risk of personality disorder, with a 5.8 hazard ratio.

We present a case report of an adult male patient who attended an appointment concerned about his violent and erratic behavior which had put him various times at odds with the judicial system. He complained about anxiety, nability to control his impulses and difficulties in maintaining relationships

\section{Identification, sociodemographics}

Male, 27 y/o, 2 children ( 7 and 9 y/o) from 2 different past relationships.

$9^{\text {th }}$ grade at $18 \mathrm{y} / \mathrm{o}$ (normal age for completion is 14)

Currently unemployed. Earns money via illegal drug related activity.

Living alone in social housing

\section{Psychiatric/Medical History}

No psychiatric history

13 ER episodes related to traumatic episodes inflicted in skirmishes and physically aggressive contexts

No ongoing Medications

Familial Psychiatric History

- Mother and father: alcohol and drug abuse

- Younger brother: ADHD at $8 \mathrm{y} / \mathrm{o}$, treated with metilphenidate with good clinical response.

Substance Abuse:

- 40 cigarettes daily

- No alcohol or drug consumption

\begin{tabular}{|c|c|}
\hline $\begin{array}{l}\text { ADHD HYPERACTIVE, } \\
\text { IMPULSIVE SYMPTOMS }\end{array}$ & $\begin{array}{l}\text { ADHD INATTENTION } \\
\text { SYMPTOMS }\end{array}$ \\
\hline $\begin{array}{l}\text { - Fidgets with hands or feet } \\
\text { - Leaves seat in classroom or } \\
\text { situations where sitting is expected } \\
\text { - Runs about or climbs } \\
\text { excessively inappropriately } \\
\text { - Has difficulty playing quietly } \\
\text { - Often on the go "as if driven by a } \\
\text { motor" } \\
\text { - Talks excessively } \\
\text { - Blurts out answers even before } \\
\text { question is completed } \\
\text { - Difficulty awaiting turn } \\
\text { - often interrupts others }\end{array}$ & $\begin{array}{l}\text { - Has difficulty sustaining } \\
\text { attention \&makes careless } \\
\text { mistakes } \\
\text { - Doesnot give close attention to } \\
\text { details } \\
\text { - Doesnot seem to listen } \\
\text { - Doesnot follow through } \\
\text { - Has difficulty organizing tasks } \\
\text { - Avoids engaging in tasks } \\
\text { requiring sustained mental } \\
\text { effort (eg homework) } \\
\text { - Often loses necessary things } \\
\text { (toys, pencil, books etc) } \\
\text { - Easily distracted } \\
\text { - Forgetful in daily activities }\end{array}$ \\
\hline
\end{tabular}
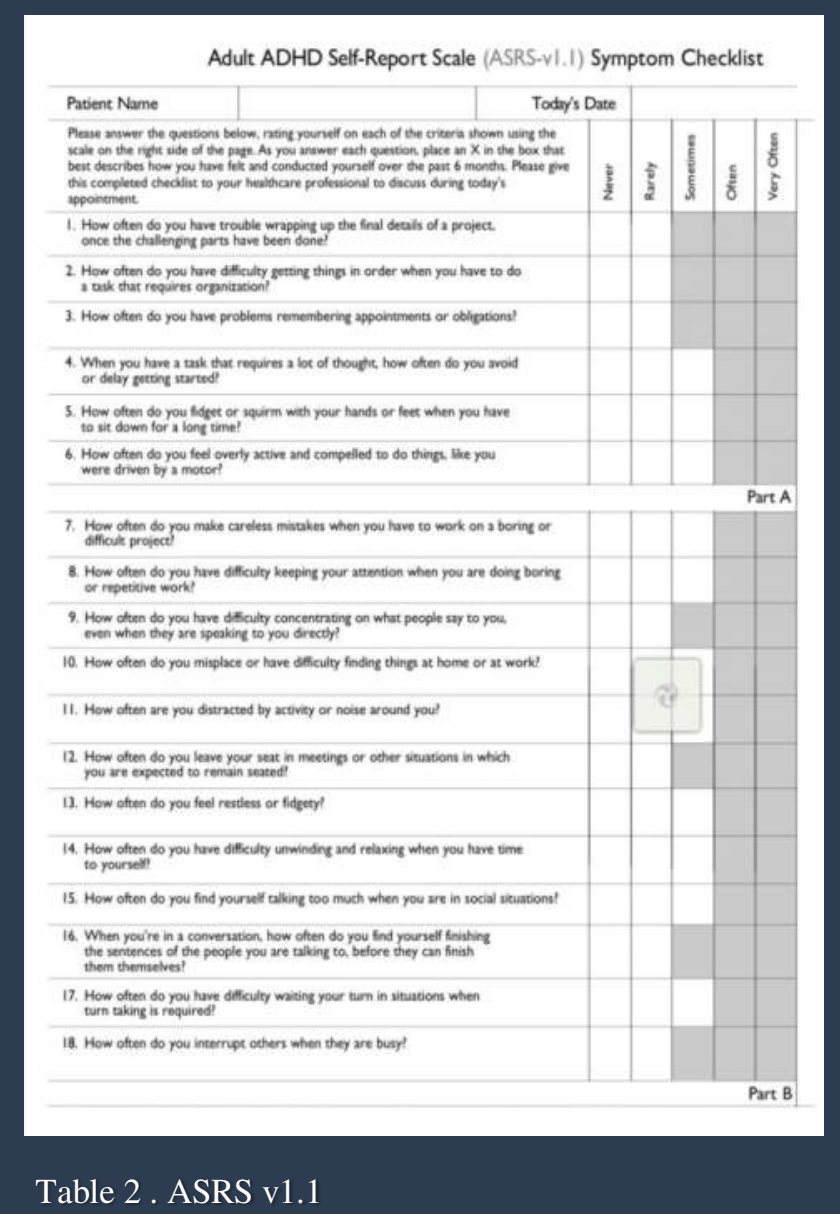

\section{Clinical Course}

\section{Main Complaints}

Persistent Anxious Mood, Difficulty controlling his impulses ("too short fused" and "unable to control myself when I get nervous"), Erratic and heteroaggressive behavior which the patient struggles to suppress, Worry about his tobacco consumption, which increases mainly during periods of more anxiety, Difficulty maintaining interpersonal relationships, Inability to focus and easy distractibility ("unworthy of trust, professionally"). Denies complaints of depressed mood or other depressive symptoms, obsessive thoughts or compulsive behavior

Psychiatric and biographical history

Pattern of disruptive behavior starting around age 16, mainly through small skirmishes with school colleagues, which progressed to criminal behavior starting at 20y/o related to drug activity (help with storing and protecting drug stashes) and a pattern of problem solving centered mainly around violence and detachment from others.

School period: Persistent difficulty in sustaining attention, staying still, following orders, as well as a constant fidgeting and feet tapping and a tendency to excessive talking (observed during the interview) and interrupting others. These complaints are present, according to the patient "since he can remember himself", and are described as impactful during childhood (mainly concerning learning) and adulthood (in previous works and interpersonal relationships).

Mental State Examination: Restless behavior, anxious mood and affect, fast paced speech, but easily interrupted. No delusions, hallucinations or behavior suggestive of such. No suicidal thoughts. No other alterations on MSE

Workup/Diagnosis, Treatment and Follow-Up

\section{Workup:}

Psychiatric interview, clinical, biographic and psychiatric history. Complete blood and urine analysis, including drug test and thyroid function All results Normal

Adult ADHD Self-Report Scale (ASRS v1.1) (table 2) - Scored 3 "often" and 3 "very often" in Part A and 7 "often" and 5 "very often" in Part B. Results suggest, in addition to and biographic history, high likelihood of ADHD.

Diagnostic: Adult Attention Deficit Hiperactivity Disorder

\section{Treatment}

- Atomoxetine $20 \mathrm{mg}$ 2id, adjusted to $40 \mathrm{mg}$ 2id a week after initial dose

Follow-up:

Patient observed on a weekly basis for three weeks and then monthly. Shown clinical improvement in anxiety and restlessness, attention deficits, focus capacity, mood, relational and impulsive behavior. Started job as a hotel clerk, reporting good adaptation and performance.

\section{Conclusion}

ADHD is still underdiagnosed in the adult population. It is an impactful clinica entity, starting during childhood, influencing development and life of an ndividual. It requires an early diagnosis and steady treatment in childhood putting poorer patients in risk of underdiagnosis or misdiagnosis. As several of ADHD symptoms can present themselves with behavioral features, such as restlessness, misbehavior in school and severe difficulty in learning, children can be put in a path of marginalization and delinquency from early on. Adding to that he increased drug consumption observed in ADHD patients (looking for the drug's "therapeutic effect") patients may present biographical history suggestive f APD, justifying the observed diagnostic overlap.

Differential Diagnosis requires attention to patient's history, chronological symptom appearance and evolution, and attention to behavio attern and empathy. ADHD symptoms should be present since early on and show predictable evolution over time. Behavior stemming from APD ndertaken with a lack of empathy and a sense of instrumentalisation of others

Of the therapeutic options available, stimulants are by far the most commonly used, but pose abuse potential, so when there is a substance abuse isk, atomoxetine is safer.

This case report highlights the importance of considering adult ADHD in patients presenting with a history of misbehavior, delinquency and symptoms of relational instability, anxiety, substance abuse, in order to allow for a partia and life-improving treatment. 